\title{
THE SHAPE OF THINGS TO COME: EX-ANTE ASSESSMENT OF THE ECONOMIC IMPACT OF HORIZON EUROPE
}

\author{
JULIEN RAVET, BAPTISTE BOITIER, MARCO GRANCAGNOLO, PIERRE LE MOUËL, LIVIU STIRBAT AND PAUL \\ ZAGAMÉ
}

DOI: $10.22163 /$ fteval.2019.337

\section{ABSTRACT}

$\mathrm{T}$ This paper provides an ex-ante assessment of the expected economic impact of the post-2020 EU Research and Innovation Framework Programme, Horizon Europe. A key novelty in the approach is the use of three different macroeconomic models for the assessment of the continuation of the current Programme, Horizon 2020: NEMESIS, QUEST and RHOMOLO. In addition, NEMESIS is used to assess different batches of policy options related to the budget, management and design of Horizon Europe. The paper also highlights key aspects and assumptions that policy-makers and researchers need to consider for this type of analysis such as budget allocation, performance, leverage and financing modes.

\section{INTRODUCTION}

EU-level investment in Research and Innovation (RqI) focuses on excellence through EU-wide competition and cooperation. Successive EU Framework Programmes have supported training and mobility for scientists, creating transnational, cross-sectoral and multidisciplinary collaborations, leveraged additional public and private investment, built the scientific evidence necessary for EU policies, and had structuring effects on national Rgl systems. The political narrative has put more and more accent on 'shaping the future' through Ryl policy and funding, thereby lending even more importance to the ex-ante assessment of the funding Programme's impact.

Horizon Europe, the 2021-2027 Framework Programme for EU R\&l, will succeed the current Programme, Horizon 2020 (active between 2014-2020). This new programme will build on lessons learnt from previous evaluations ${ }^{1}$, feedback from experts ${ }^{2}$ and from other stakeholders. It will be an evolution, not a revolution, focusing on a few design improvements to further increase openness and impact. With Horizon 2020 well on track to deliver excellence, these changes in the design aim at making the successor Programme achieve even more impact (through the European Innovation Council and mission-orientation) and more openness (through strengthened international cooperation, a reinforced Open Science policy, and a new policy approach to European Partnerships).

Assessing the impact of the Framework Programmes ex-ante is crucial for policy-makers in order to inform their strategic decisions. There is a general consensus (Hall, Mairesse and Mohen, 2009; European Commission, 2017a; Di Comite and Kancs, 2015) that R\&l are decisive in fostering productivity growth. However, putting a precise figure on the expected benefits of a large Ryl programme is a challenging task with a lot of uncertainties, notably due to the ex-ante approach. This is made even more difficult by the long-term horizon that a proper analysis of these impacts requires.

This paper aims at providing an assessment of the expected economic impact of the post-2020 Framework Programme. It also highlights key aspects and assumptions that policy-makers and researchers need to consider for similar analyses, especially when they need to collaborate with each other.

\section{MODELLING THE IMPACT OF THE EU FRAMEWORK PROGRAMME}

The first ever ex-ante impact assessment of any EU policy initiative in the field of research was the impact assessment of the 7th Framework Programme (FP7) (Muldur et al., 2006; Delanghe and Muldur, 2007). The quantification of its economic impact relied on historical data (e.g. publications and patents) and on simulations based on macroeconomic modelling. The NEMESIS model was used for this impact assessment, and subsequently for the impact assessment of Horizon 2020 (European Commission, 2013).

Since FP7, macroeconomic models, including NEMESIS, have evolved and lessons from previous impact assessments can help policy-makers in using these models for current and future assessments.

In this context, macroeconomic modelling is an essential tool to support policy-making by quantifying the impact of the Programmes and assessing policy options. Depending on when the assessment takes place in the EU policy cycle (Figure 1), this can be done in an ex-post/interim (monitoring and evaluation of a programme) or ex-ante design (impact assessment), with policy options examined in impact assessements only in order to feed the preparation phase of the Programmes. 


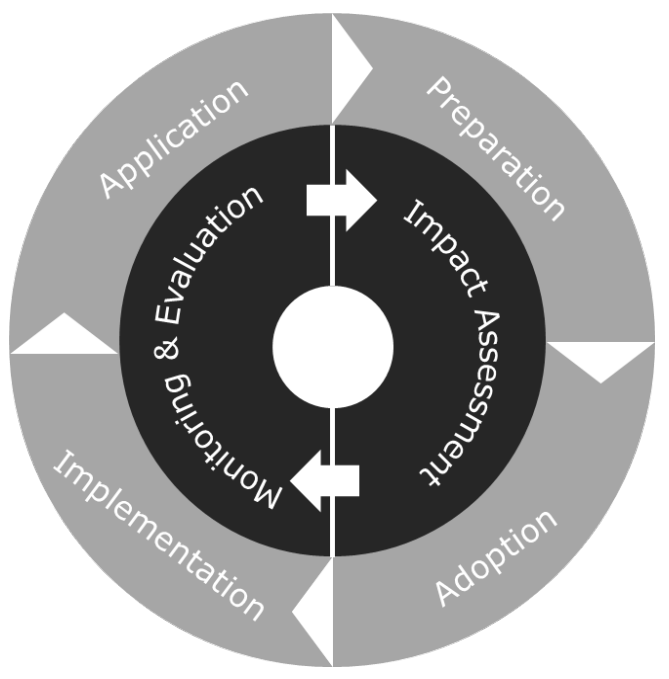

Figure 1 EU policy cycle

Source: adapted from the EU Better Regulation guidelines (European Commission, 2015).

Expanding on the Horizon Europe Impact Assement (European Commission 2018), in this paper the NEMESIS, QUEST and RHOMOLO 3 models are used to assess the impact of the continuation of Horizon 2020 in order to triangulate the signs, patterns and sizes of the impact of continuing the current Framework Programme. To the authors' knowledge, this is the first time that results from different models are triangulated to assess the impact of EU R\&I funding. By relying on these three models, the aim is to leverage on their respective strengths and compensate for their limitations. The strengths of these models rely on their specificities, and the differences between the models can help address specific needs of policy-makers. When using and interpreting results produced by these models, it is also essential to acknowledge their main limitations, as any model only allows for a partial representation of reality subject to the assumptions made.

NEMESIS is a macro-econometric model consisting of detailed sectoral models for every EU country. Measuring technical progress in NEMESIS is derived from the new growth theories where innovations result from the investment in R\&D by private firms, and from R\&D undertaken by the public sector. In the latest version of NEMESIS used for this paper, innovations still arise from private and public investments in R\&D, but also from investments in two other complementary innovation inputs: ICT and Other Intangibles (including training and software). These enable improved accuracy in assessing R\&l policies by considering the most up-to-date theoretical and empirical findings of economic literature (Le Mouël et al., 2016). Di Comite and Kancs (2015) consider that NEMESIS is the richest model in terms of innovation types and policy elasticities when compared to other standard macroeconomic models for R\&D and innovation policies. This means that policy-makers can easily design options related to specific innovation types or innovation channels when using this model. However, NEMESIS is based on empirical observations of relationships among variables as well as on adaptive expectations instead of forward-looking ones, allowing for more degrees of freedom in behaviour than in other models. This may generate inconsistencies with recent developments in macroeconomic theory.
QUEST belongs to the class of micro-founded dynamic general equilibrium (DGE) models that are now widely used in economic policy institutions as the latest step in the development of macroeconomic modelling. The focus in these models is on the economy as a whole, as an integrated system of economic agents that base their decisions over a range of variables by continuously re-optimising while subject to budgetary, technological and institutional constraints. These models are forwardlooking and intertemporal, i.e. current decisions account for expectations about the future. This analysis uses the semi-endogenous growth version of the Commission's QUEST model with an R\&D production sector (QUEST3RD). The model economy is populated by households, firms producing final and intermediate goods, a research industry and a monetary and fiscal authority. The forward-looking dynamic approach of QUEST makes the model the most appropriate for assessing the impact of R\&D and innovation policies over time. This is particularly important as effects of the initial investment are expected to last after the period covered by the Programme, which calls for a model that can precisely measure long-term impacts. On the other hand, QUEST III, being an aggregate macroeconomic model, groups all R\&D activities in a unique R\&D sector without capturing the complexity and diversity of the type of R\&D investments (e.g. private and public R\&D activities, product and process innovation, non-R\&D, and disruptive innovations) or their extensive sectoral and geographical details.

RHOMOLO is a spatial DGE model that covers 267 regions at the NUTS2 level. Each region contains 10 economic sectors. A subset of these operates under monopolistic competition. The rest of the sectors operate under 'perfect' competition. Regional goods are produced by combining labour and capital with domestic and imported intermediates, creating vertical linkages between firms. By modelling regional economies and their spatial interactions, RHOMOLO is the most suitable model to address questions related to geographic concentration of innovative activities and spatial knowledge spillovers, which is also a crucial aspect for policy-makers. However, RHOMOLO trades off its detailed spatial dimensions with keeping the optimisation problems static and, hence, not capturing the inter-temporal consequences of innovation decisions. In addition, it does not distinguish between private and public innovation or between different types of endogenous innovation.

\section{TAILORING THE MODELS TO THE SPECIFICITIES OF THE EU FRAMEWORK PROGRAMME}

The three macroeconomic models do not initially reflect the reality of the EU Framework Programme. In order to adapt the models to the specificities of the programme, several parameters and assumptions need to be carefully considered.

The budget of the Programme is a first key element to specify. This entails the overall amount that will be spent, but also the temporal, national and sectoral allocation of the budget. Depending on the mechanisms of the model, additional dimensions can be added: the regional allocation (at NUTS2 level) for RHOMOLO, or the allocation between basic and applied research for NEMESIS. For the assessment of Horizon Europe, budget size and budget allocation ${ }^{4}$ are assumed to be the same as in Horizon 2020 in the baseline scenario (i.e. the continuation of Horizon 
2020 over 2021-2027), in constant prices and without the contribution of the UK (around 15\% of the Horizon 2020 budget). This corresponds to about 85 billion euros in current prices over 2021-2027 based on the last year of Horizon 2020.

An essential aspect for all models is the mode of financing of the Framework Programme. Money spent for the Framework Programme can come from different sources, and in this regard, it is tempting but rather unrealistic to make it appear out of nowhere. In this paper, RHOMOLO and NEMESIS assume that the financing of the Programme can be reflected by lowered national expenditure. The mechanisms of QUEST can be used to assess two financing scenarios: (i) raising additional VAT revenues in the Member States and (ii) lowering national public investment.

A feature that is specific to the NEMESIS simulations is the use of different parameters for leverage ${ }^{5}$ and economic performance ${ }^{6}$ of EU RYI funding compared to national funding. The model assumes parameters that reflect a European Added Value of R\&l funding: a better leverage of European funding when compared to national ones inducing more R\&l expenditures for the same level of public funding 10.15 instead of 0.1 for applied research), and a higher research productivity (15\%, also used in European Commission, 2013) of the European Ryl Programme, explained by the higher competition at the European level than at the national one, and by the transnational collaborative aspects inducing more knowledge spillovers. This EU added value is supported by several studies (ECDG and Elsevier, 2017; Rosemberg et al.; 2016; Vullings et al.; 2014; Delanghe et al., 2011; PPMI, 2017). Values used for these parameters in the NEMESIS model are considered to be conservative with regards to the literature, including the following quantified results from PPMI (2017) based on data from the 7th Framework Programme (FP7) and Horizon 2020:

- Research organisations supported by FP7 are around $40 \%$ more likely to be granted patents or produce patent applications.
- Patents produced in FP7 are of higher quality and likely commercial value than similar patents produced elsewhere $170 \%$ more citations).

- Patents produced under the Framework Programmes are likely to be of higher technological value and more likely to be based on cutting edge scientific knowledge ( $11 \%$ more citations in FP7).

Horizon 2020 participants declare that the programme significantly improves their competitive position internationally (78 \% expect a decrease in this area if they had not been funded) and access to new markets (71\% expect a decrease in this area if they had not been funded).

\section{BASELINE SCENARIO: HOW MUCH IS THE CONTINUATION OF HORIZON 2020 WORTH?}

NEMESIS, QUEST and RHOMOLO are used to assess the impact of the continuation of Horizon 2020 compared to a situation without a Framework Programme (i.e. discontinuation). This scenario assumes that EU funding for R\&I will be carried over 2021-2027 with a similar budget as in Horizon 2020 (see Section 3). The three different models correspond to different approaches and present very different specifications and settings of parameter values. One should therefore not expect the three models to produce identical estimates of the economic impact of a given policy intervention. However, comparing the findings from the three models for the continuation of Horizon 2020 allows to triangulate results in order to assess the consistency of the impacts identified in each model. This triangulation is also essential for a better understanding of how the specific mechanisms of these models can affect the results they produce.

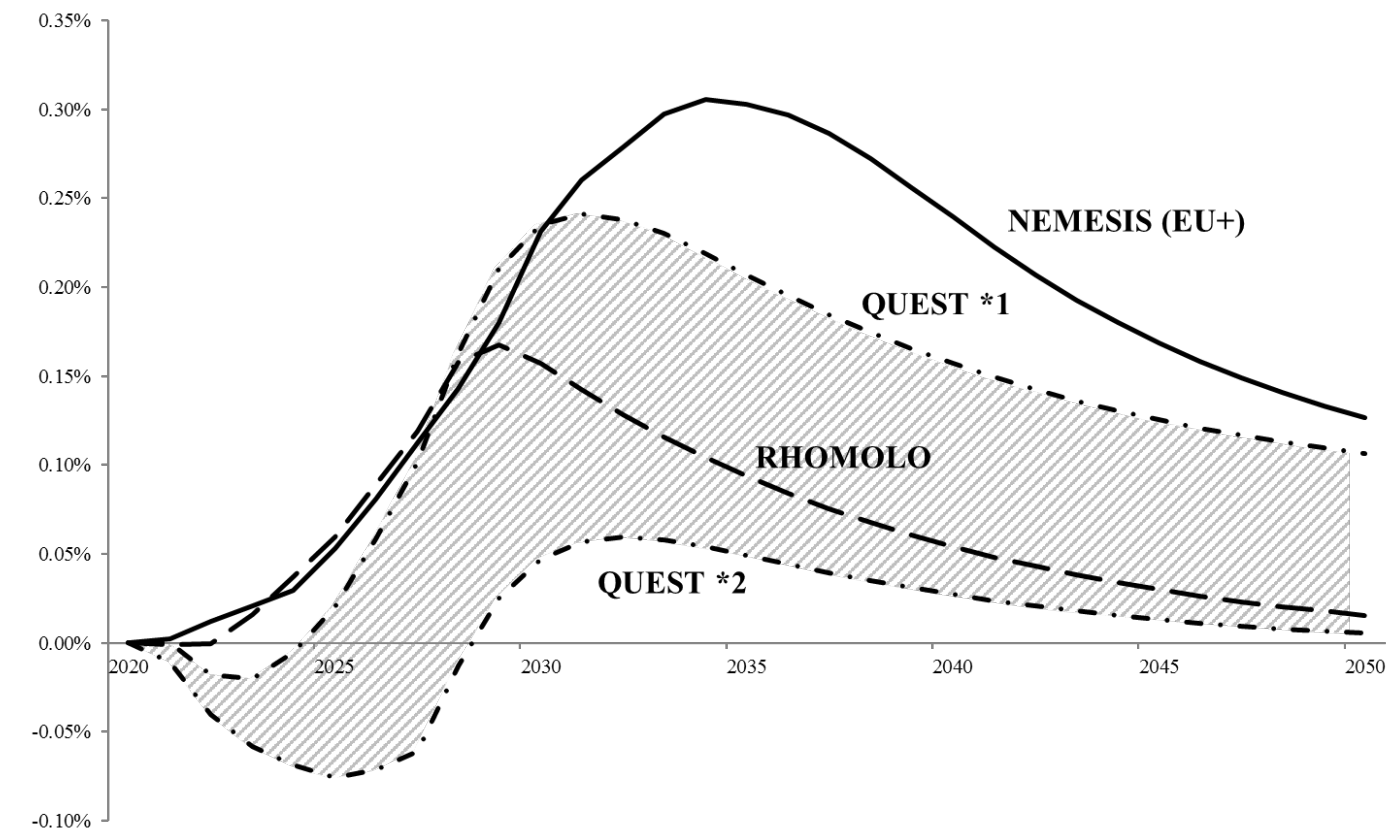

Figure 2 GDP impact of Horizon 2020 continuation (deviation in \% from a discontinuation)

Source: Seureco (NEMESIS) and European Commission (RHOMOLO and QUEST). Note: EU+ indicates that Nemesis uses higher performance and leverage for EU funding compared to national funding as a reflection of the EU added value of the Programme. OUEST * 1 assumes that financing of the Programme relies on VAT increase. QUEST *2 assumes that financing relies on lowering public investment. 
The models present consistent results in terms of sign and temporal pattern of the GDP gain from the Framework Programme (compared to the discontinuation of the Programme) over 2021-2050 (Figure 2). The three models show a strong increase in the GDP impact during or after the period covered by the Programme, with highest impacts expected between 2029 and 2034. The size of the GDP gain is the highest based on the NEMESIS results. This can be explained by the fact that the three models use different sets of innovation channels and elasticities. These results suggest that the continuation of the Framework Programme after 2020 is expected to bring an estimated average GDP increase of up to $0.19 \%$ over 25 years, which means that each euro invested can potentially generate a return of up to 11 euros of GDP gains over the same period.

The highest gains in the NEMESIS model can be partly explained by the fact that QUEST and RHOMOLO do not directly take into account the higher leverage and performance expected from EU funding of Ryl compared to national funding, while this is acknowledged in the parameters of NEMESIS. As explained in Section 2, this assumption reflects the intrinsic EU added value related to the EU level investments due to factors that are not directly captured by these models, such as multidisciplinary transnational collaborations or critical mass.

Regarding the mode of financing, results from QUEST show that financing R\&I investments from value added taxes produces higher economic benefits in the model in the medium and long run than with public investment cuts. This is because the financing mechanism in the model attributes potential productivity effects to public investments (e.g. roads, buildings) which are higher than for value added taxes.

The pattern in time is similar between the models. The NEMESIS model describes this pattern with the following three main phases. (i) An investment phase over 2021-2027 that is a 'demand phase' in which all the dynamics are induced by the change in the R\&l expenditures, with or without moderated impacts of the innovations (as they take time to appear). This phase can be viewed as a Keynesian multiplier. (ii) The innovation phase: the arrival of innovations reduces the production cost of the new products or raises their quality, which induces an increase of demands for products. (iii) The obsolescence phase: new knowledge progressively declines due to knowledge obsolescence and, in the longterm, the macro-economic track goes back to the reference scenario.

The impact on jobs based on the NEMESIS model is also substantial (Figure 3). EU investments in R\&l are expected to directly generate an estimated gain of up to 100,000 jobs in R\&l activities in the "Investment phase" (2021-2027) and to foster through the economic activity generated by the Programme an indirect gain of about 200,000 jobs over 2027-2036, of which $40 \%$ are high-skilled jobs. However, during the investment period, while the Programme has a positive effect on jobs in R\&l, the decrease in national public investment that is assumed by the model is mechanically accompanied by a comparable decrease in non RYl-related jobs. During this period, the increase in R\&I investment raises the demand for employments in research activities. But the funds used to support R\&l activities are taken from national public investments according to the assumption used in the model. This shift between both kinds of investments explains the decrease of high- and low-skilled employment while employment in research activities increases. Furthermore, the raise of the demand for employment in R\&l activities increases the inflationary pressure on the high-skilled workers' wages (as employment in R\&l activities are mainly provided by high-skilled workers). This reinforces the negative impact on high-qualified employment during the investment phase.

After the investment phase, total employment rises progressively to reach a maximum deviation of $+228,000$ employments in 2036 compared to a situation without Framework Programme. Between 2028 and 2036, around $60 \%$ of the cumulative EU employment gains relate to low-qualified workers, $30 \%$ to high-qualified workers and $10 \%$ to employments in research activities. After 2036, the declining economic gains resulting from the EU R\&I Programme also reduce employment gains.

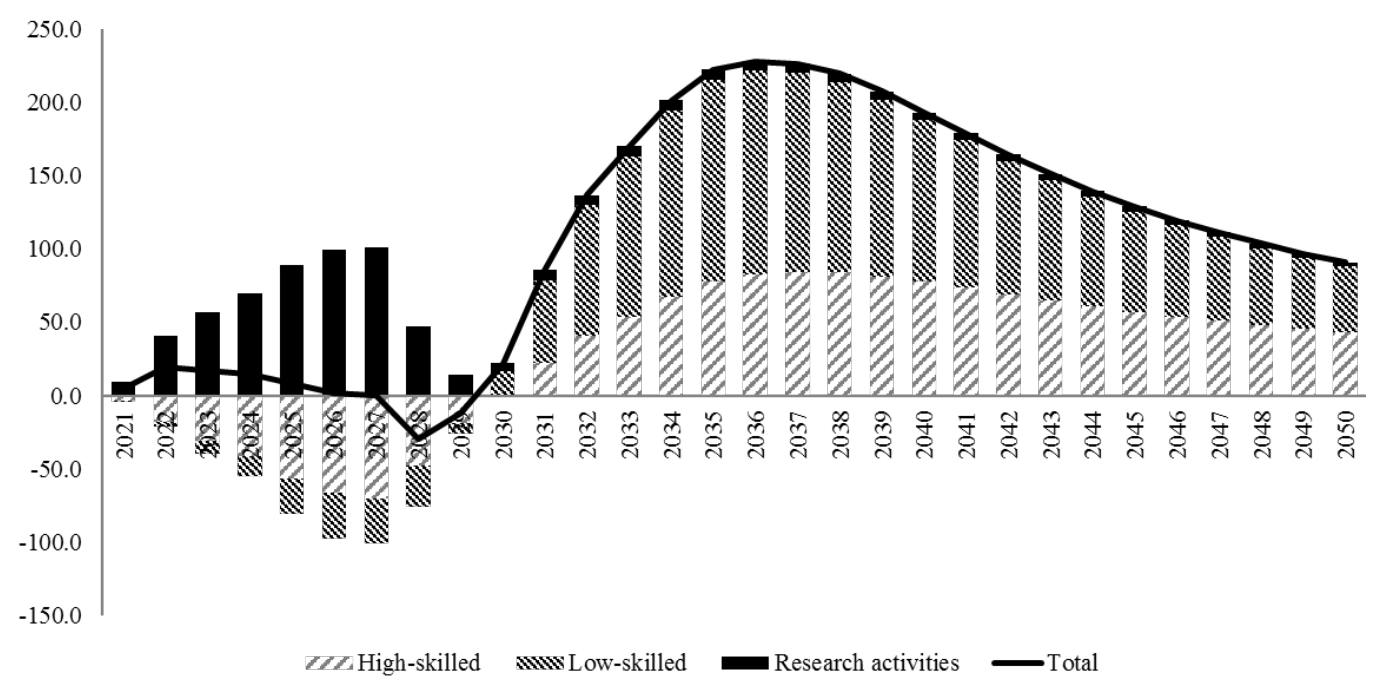

Figure 3 Decomposition of employment impact of the continuation of Horizon 2020 (NEMESIS, deviation in thousand jobs from a discontinuation) Source: Authors' calculations. 


\section{ASSESSING THE IMPACT OF POLICY OPTIONS}

The NEMESIS model is used to assess different sets of policy options for Horizon Europe by changing specific parameters of the model. The impact of these options is assessed against the baseline, which is the continuation of Horizon 2020 (as described in section 4). Besides the parameters changed for each option, all assumptions are the same as in the baseline scenario.

\subsection{ASSESSING BUDGET OPTIONS}

A first element that is critical for Horizon Europe is the budget allocated to the Programme. Different budget envelopes for Horizon Europe

(a) \% GDP deviation from baseline

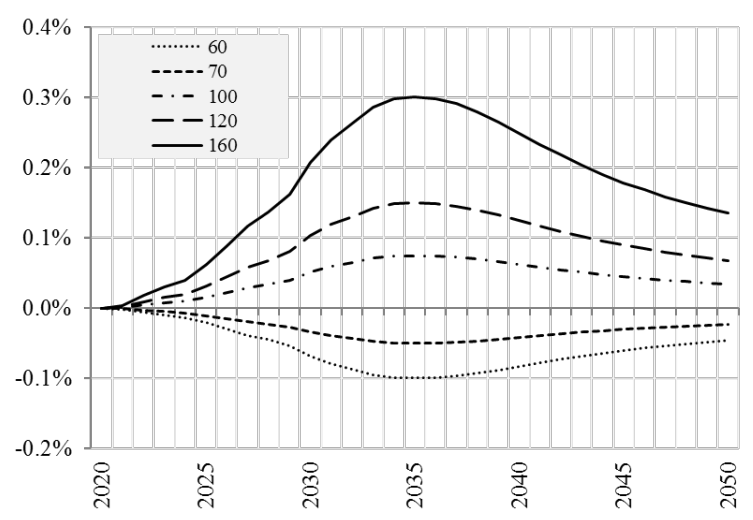

(c) Employment deviation from baseline (thousand)

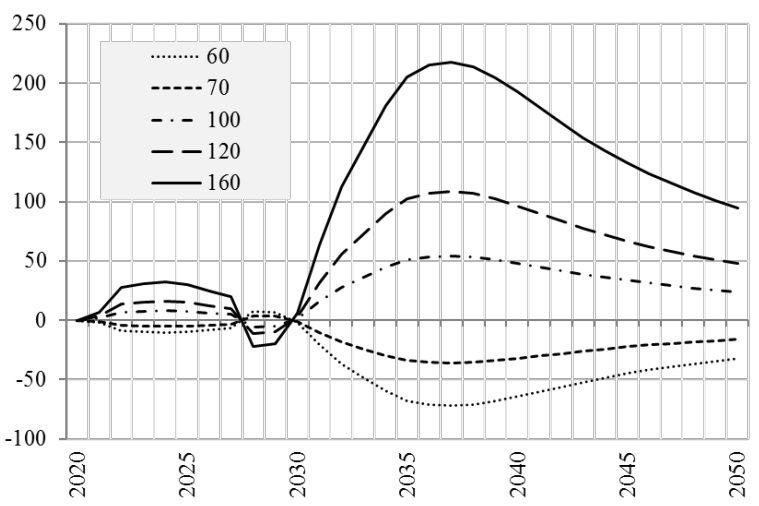

are assessed ${ }^{7}$, ranging from EUR 60 billion to EUR 160 billion in current prices. Variations of the EU budget envelope around the baseline are compensated by equivalent variations of national public investments. In modelling options with lower budget compared to the baseline scenario, funds that are not used for Horizon Europe are "given back" to EU Member States (according to their contribution to the EU budget) and used in public investments (excluding research activities), i.e. gross fixed capital formation. Modelling options with higher budget assume that each Member State raises its contribution to the EU budget and finances this transfer to the EU by reducing its public investments accordingly. This does not correspond to a "centralisation" of Ryl funds at EU level, as the budget variations of Horizon Europe are compensated by variations from national investments excluding R\&I investments and not by variations of national public support to R\&l (this aspect is addressed in section 5.2).

\section{(b) Average contribution to GDP deviation from base- line}

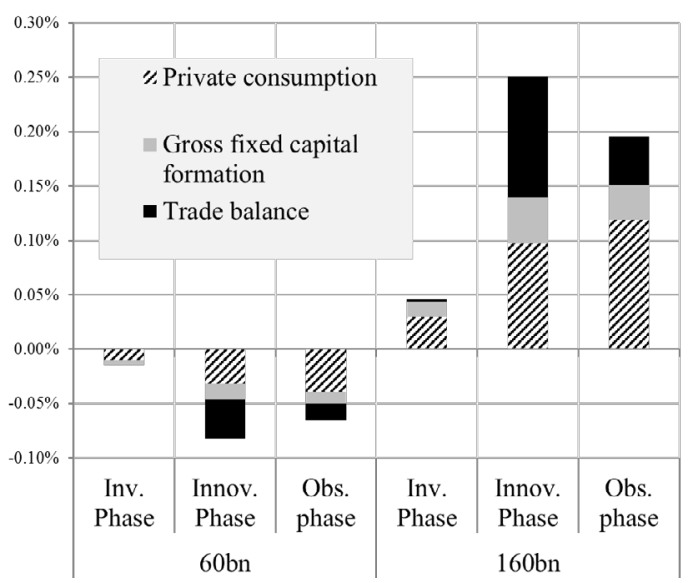

(d) Average annual employment deviation from baseline (thousand)

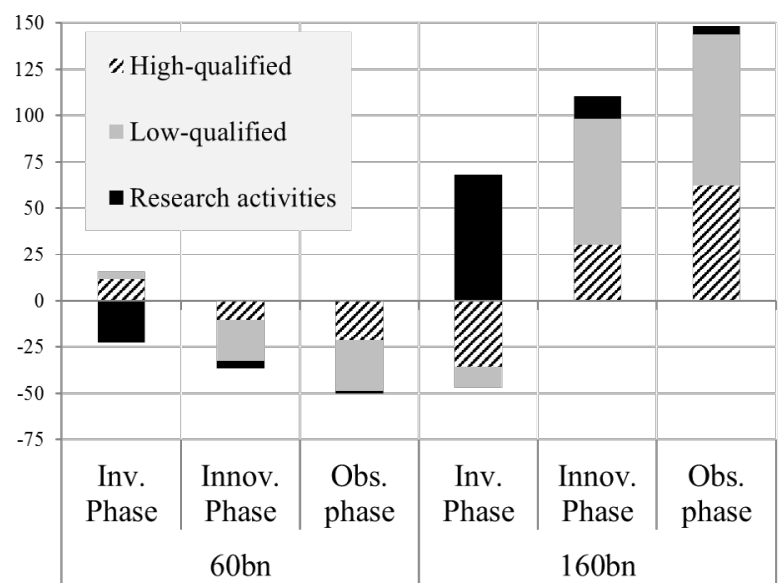

Figure 4 Impact of budget options compared to the H2020 continuation scenario (baseline)

Source: Authors' calculations. 
As shown in Figure 4a, the sign of the GDP variation follows the direction of the budget change, with options with largest and lowest budget envelope presenting respectively the largest and lowest impacts. The main driver of the impact size is the difference between the productivity of R\&I investments and public investments (excluding R\&I) as budget deviations are financed by an opposite deviation of the public gross fixed capital formation. During the investment phase (2021-2027), the EU GDP deviation under each budget option is relatively contained as the effects of the innovations resulting from $R \& 1$ investments do not yet operate fully during this phase. After 2027, the GDP deviation with respect to the baseline scenario becomes increasingly important, and reaches a maximum around 2035. In the EUR 60 billion scenario, the EU GDP deviation reaches a minimum of $-0.1 \%$ in 2035 . In the scenarios with higher EU RYI budget, the deviations of the EU GDP can be significant, and reach a maximum of $+0.3 \%$ in the EUR 160 billion scenario.

The decomposition of the EU GDP deviation (Figure 4b) in the lowest and highest budget options shows that the main contribution to the EU GDP deviation during the investment phase comes from the private consumption. After the investment phase, the trade balance becomes the most important contributor to the GDP deviation, with R\&D intensive sectors being also the most open sectors to international markets. During the obsolescence phase, productivity gains are progressively spread to the overall economy, thus increasing real wages and reinforcing the contribution of private consumption to EU GDP deviation.

Regarding the impact on employment, (Figure 4c), the strongest deviation of total EU employment with respect to the baseline scenario is reached in 2037, with -72,000 thousand jobs in the EUR 60 billion scenario and $+217,000$ thousand jobs in the EUR 160 billion scenario. The employment deviation follows the same pattern as the GDP deviation after the end of the Programme, with an intensification of the deviation followed by a progressive decrease. However, in 2028 and 2029, due to the end of the EU support to Rql, combined with the effect of changes in real wages, especially for high-qualified workers, the impact on EU total employment is opposite compared to other periods. For example, in the EUR 120 billion scenario, the EU total employment is lower than in the baseline scenario, with $-11,000$ and $-10,000$ employments in 2028 and 2029 respectively.

In terms of types of jobs (Figure 4d), budget deviations directly impact R\&l employment during the investment phase. Under the lower budget options, the reduction of EU support to $R \& \mid$ induces a decrease of $R \& \mid$ employment compared to the baseline scenario (with up to $-40,000$ in the EUR 60 billion option, and $-20,000$ in the EUR 70 billion option) but the increase in public investments (as a result of the reduction of EU budget to R\&I) positively impacts high-qualified and low-qualified employment. The patterns are reverted for options with higher budget. After 2027, employment in R\&l activities is close to the baseline level in all scenarios.

\subsection{ASSESSING (DE)CENTRALISATION OPTIONS}

While budget options in Section 5.1 considered that changes in the envelope of the Framework Programme can be reflected by corresponding changes in national investments, another approach is to shift R\&l efforts between the different levels of intervention, i.e. national and EU level. This type of shift corresponds to a "centralisation" or "decentralisation" of the management of Ryl funds. The impact of two options are assessed with respect to the central management of the Framework Programme: an option with more centralisation of EU funds for R\&l at EU level and an option of more decentralisation at national level. The option with more centralisation is defined as a reinforcement of the Framework Programme after Horizon 2020 by centralising, at EU level, one third of the national competitive-based project funding (i.e. $8.75 \%$ of the national public R\&D expenditures ${ }^{8}$ ). As a result, the total budget for Horizon Europe is EUR 160 billion (in current prices), which also corresponds to the highest budget option in Section 5.1. In the decentralisation scenario, the EU R\&I programme is implemented at national level: EU funds for Ryl over 2021-2027 are redistributed to Member States, who use them to support national $R \& 1$ activities.

Figure 5 shows the impact of these options on EU GDP. Under the option with more centralisation, after 2027, innovation starts to diffuse widely into the economies and, as the amount of EU support to RqI activities is almost twice that invested in the continuation scenario, the positive impact in terms of innovation and, then, economic performance is higher. In this scenario, the EU GDP gain compared to the baseline scenario reaches a maximum of $+0.21 \%$ in 2031 as the result of two main factors: (i) due to the initial allocation of funding at national and EU level used in the model, there is a shift towards more applied research (associated with more impact on absorption capacity and leverage); (ii) the economic performance is stronger when funds are used at EU level compared to national level. From 2028 to 2034, when more and more innovations enter the market, the EU GDP in the centralisation scenario progresses more rapidly than in the continuation scenario, with a maximum difference in 2031 of $+0.21 \%$. Under the decentralisation option, the observed deviation of the EU GDP is negative, but relatively limited.

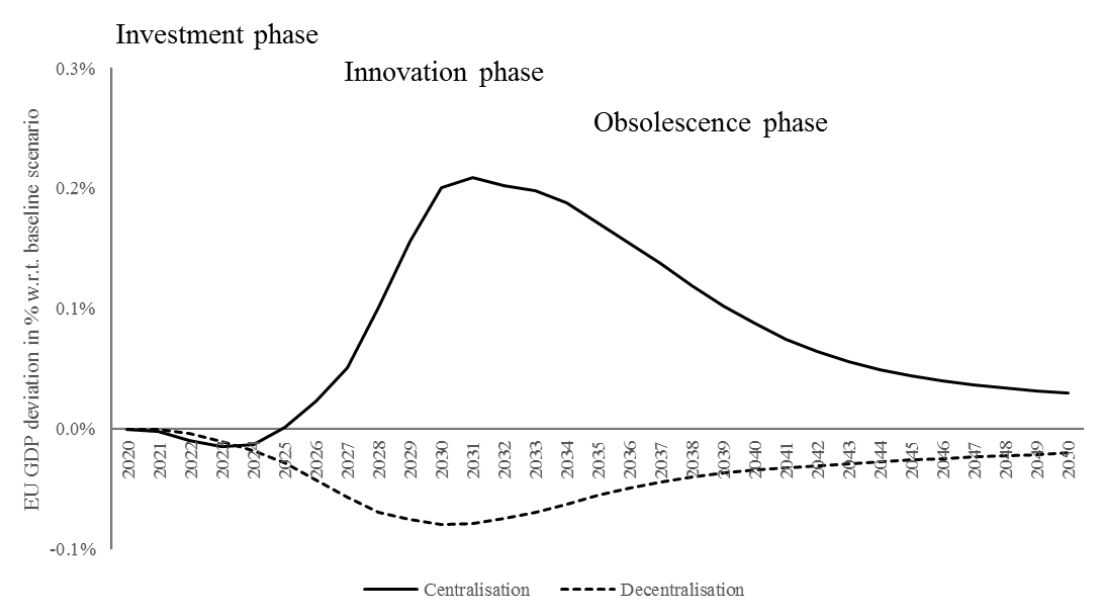

Figure 5 EU GDP deviation in the de(centralisation) options (\% w.r.t. the baseline scenario) Source: NEMESIS model 
Deviations in terms of employment are reported in Figure 6. With more centralisation, total EU employment is moderately lower than in the baseline scenario during the investment phase (2021-2027) with $-59,000$ jobs in 2026. This lower EU total employment is the combined result of three different mechanisms. (i) The higher investments in Rgl activities (explained by higher crowding-in) increase the inflationary pressure on the high-qualified labour market. (ii) There is a reallocation of the funds between the two types of research (from basic to applied) that do not have similar labour contents. (iii) The reallocation of public Ryl funding to beneficiaries through EU funding is not ex-ante neutral for all Member States: some of them lose funds whereas others win. Af- ter 2027, however, when innovation takes place, EU total employment in this centralisation scenario is higher than in the baseline scenario, with a maximum EU total employment gain of 175,000 units in 2034, of which 111,000 in low-qualified jobs, 60,000 in high-qualified employments and 4,000 in research activities. The decentralisation option shows a negative impact on the EU total employment in comparison with the baseline scenario: the maximum loss of EU total employment reaches 78,000 units in 2031 (49,000 low-qualified jobs, 27,000 high-qualified jobs and 2,000 jobs in Ryl activities). In 2050, the difference is almost nil with $-10,000$ employments under the decentralisation option compared to the baseline scenario.

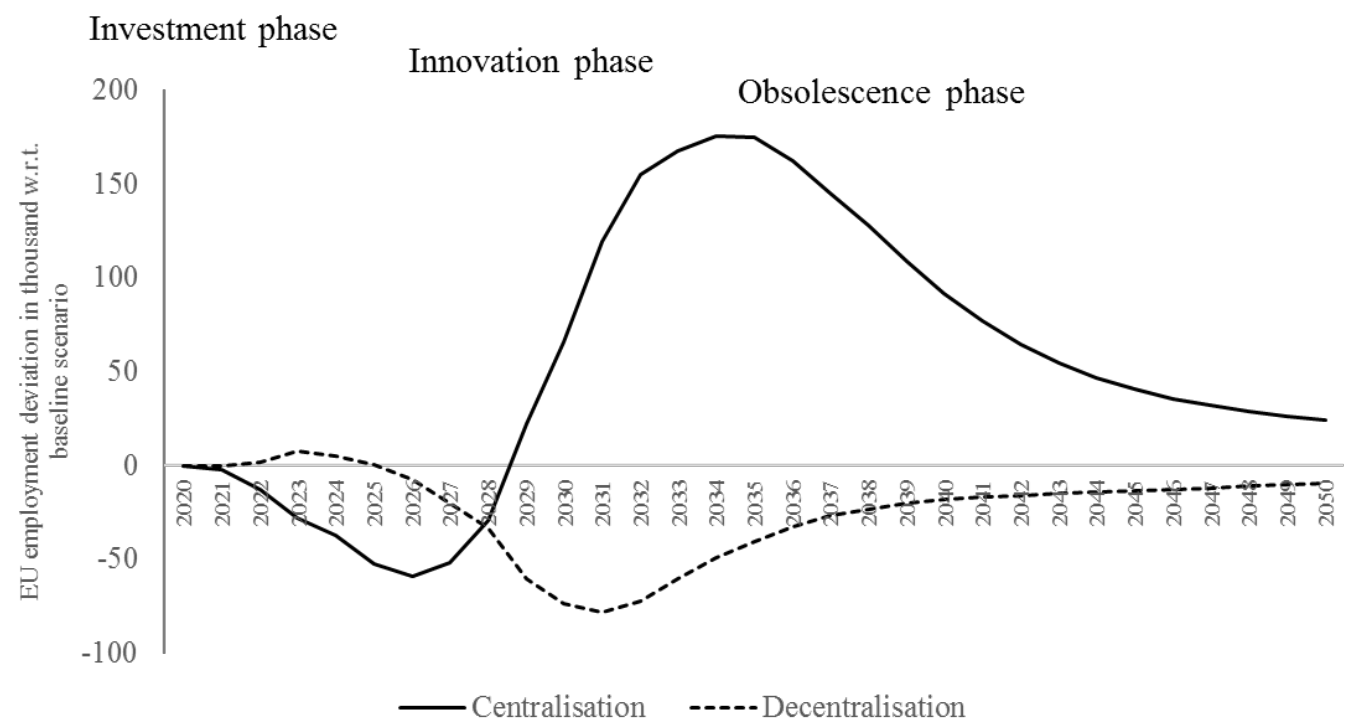

Figure 6 EU employment deviation in the de(centralisation) options (\% w.r.t. the baseline scenario)

Source: NEMESIS model

It is important to stress that these results strongly depend on the assumptions of higher leverage and economic performance of Ryl at EU level compared to national level (see Section 3), which is the direct translation in the model of the EU added value of RYI funding. Sensitivity analysis carried out on the parameters of the model (see Boitier et al., 2018) shows that the higher direct leverage of EU financial support to applied research compared to national support has a moderate impact on EU GDP and total employment, while the higher economic performance of the R\&l activities engaged at EU level compared to similar activities at national level is the key explanatory factor behind the impacts. As developed in section 3, evidence on this higher EU performance of Rgl funding can be found in the literature. However, its precise quantification is not straightforward. This is why this paper uses conservative values with respect to existing evidence (see Boitier et al., 2018 for a survey of the related literature). However, it is worth stressing that the model cannot demonstrate as such that RYI at EU level performs intrinsically better than at national level (as, for example, due to multidisciplinary transnational collaborations or critical mass).

Another important aspect regarding the centralisation option is that it considers a total envelope of EUR 160 billion for the Framework Programme, which is also the highest budget option in Section 5.1. While budgets are the same under both options, the assumptions behind the budget increase compared to the baseline are different: in the centralisation scenario, funds for Ryl are shifted from national to EU-level, while the budget increase considered in section 5.1 is compensated by a decrease in national investments. As a result, the centralisation scenario produces lower results compared to a scenario where national funds for RyI are not decreased. Hence, this result shows that an increase in EU budget for $R \mathscr{C l}$ is more beneficial if it does not crowd out national $R \mathscr{l}$ support.

\subsection{ASSESSING CHANGES IN THE DESIGN OF THE PROGRAMME}

Changes in the design of Horizon Europe compared to Horizon 2020 (European Commission, 2018) aim at even more impact and openness. This will be achieved through several features such as the European Innovation Council, the mission-orientation, a strengthened international cooperation, a reinforced Open Science policy, and a new policy approach to European Partnerships. Assessing the overall impact of these changes is a very challenging exercise, as they correspond to several incremental improvements that are expected to affect different aspects of the Programme. 
It is important to highlight the extent to which potential improvements in the design of the future Programme can enhance its impacts. This can be achieved in two steps. First, the impact of expected changes can be translated in changes in specific parameters of the model, which need to be identified. Second, the variation of these parameters needs to be quantified. This quantification is the most difficult task, as a lot of uncertainty encompasses the future response of key parameters such as performance or leverage to these changes. The impact of the changes also depends strongly on the effectiveness in their implementation in the future Programme. Hence, while the impacts of these changes is expected to be positive, their size is uncertain. Therefore different scenarios are considered, from low to high, by using ranges in the variation of the parameters. These ranges rely on plausible values found in the literature, with extreme values showing how impactful Horizon Europe can be in the most ambitious and optimistic conditions.

The following parameters were adjusted in order to reflect the impact of the changes that could be implemented in Horizon Europe. Adjustment of parameters that correspond to changes in the design of the Programme to increase impact and openness are the following:

- Higher economic performance: Horizon Europe will aim for higher economic impacts, including more market-orientation. This is translated in the model by modifying the performance of the EU R\&I programme (from +0 in a 'low' scenario to +5 percentage points in a 'high' scenario compared to the baseline).

Lower knowledge obsolescence: Horizon Europe will focus on more breakthrough innovations and create more fundamental knowledge that could make innovations last longer in time. The NEMESIS model uses a depreciation rate of $15 \%$, which is widely used in the empirical literature (see e.g. Corrado et al., 2016). In a 'low' case, we retain an obsolescence rate of $14 \%$, increasing from 5 to 6 years the average life duration of the knowledge created. In the "high" case, this duration reaches 6.5 years.

- Stronger complementarities with other innovative assets: this should be reinforced by the the more cross-technological and cross-sectoral R\&l supported, and more focus on breakthrough technologies and mission-orientation. Complementarities are reinforced by $5 \%$ a "low" scenario and 10\% in a 'high' scenario.
- Higher direct leverage of private R\&D: Horizon Europe should enable a better access to finance for breakthrough innovating start-ups. The main expected impact should therefore be an enhancement of the direct leverage of the EU support on private firms' Rgl investment. In a 'low' scenario, leverage is the same as in the baseline for applied research (0.1), while it corresponds to the upper bound of the estimated range of the meta-analysis conducted by Dimos and Pugh (2016) in the 'high' scenario.

- Higher complementarities with national support to R\&D: the programme is expected to increase complementarities between EU and national supports to Ryl. This should reinforce national support to $R \& D$, which is financed in the model by an equivalent reduction of other public investments (excluding R\&I activities). This is translated indirectly in the model by an increased leverage of EU support on national support (adjusted here through increased leverage for basic research, set at 0.05 in a 'low' scenario and 0.1 in a 'high' scenario).

- Stronger knowledge diffusion: Horizon Europe should facilitate knowledge diffusion, encouraging multi-disciplinary collaborations, international cooperation and open science. Based on the literature, reasonable values, in the light of the progress achieved between FP7 and Horizon 2020 in terms of knowledge diffusion (see e.g. Vullings et al., 2014, or European Commission 2017a) should reflect increased knowledge spillovers compared to the baseline scenario: values used in this paper are $+5 \%$ in the 'low' scenario and $+10 \%$ in the 'high' scenario.

Results of all these changes in terms of GDP deviation according to the 'low' and 'high' scenario are presented in Figure 7. Compared to the continuation of Horizon 2020, changes in the programme's design can potentially generate an additional GDP gain up to $0.04 \%$ in a low scenario, and up to $0.1 \%$ in a high scenario. The impact of the changes is expected to be most significant after 2030. The total impact of the programme on EU GDP would be between EUR 800 billion and EUR 975 billion over 25 years $^{10}$.

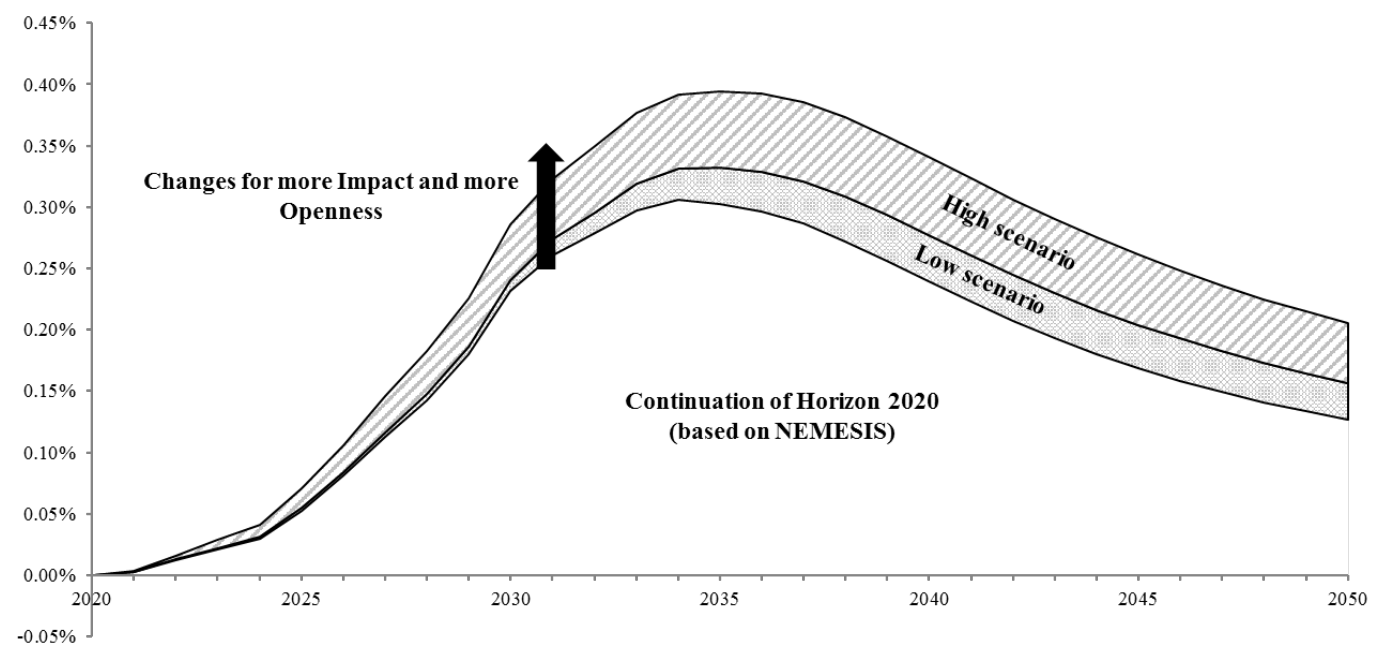

Figure 7 Impact of the changes in design (GDP gain, compared to a situation without Framework Programme)

Source: Authors' calculations. 
When combining the improved design of the programme with the budget proposed by the European Commission for Horizon Europe (EUR 100 billion in current prices), results from the NEMESIS model suggest that the estimated total impact of the Programme is even higher. In comparison to a case with no Framework Programme, the programme could generate up to $\sim$ EUR 45 billion $^{11}$ per year over 25 years ( EUR 1100 billion in total), i.e. up to 11 euros of GDP gains per euro invested over 25 years. Moreover, Horizon Europe could create up to 140,000 units of employment in R\&I activities during its lifetime (2021-2027) and up to 340,000 units afterwards (figures based on maximum employment deviations estimated by the model). This corresponds to an average deviation of total employment of 170,000 units over the period compared to a situation without Framework Programme.

\section{CONCLUSION}

This paper shows how current models can be applied in assessing ex-ante the impact of a large and complex Ryl Programme such as Horizon Europe. While the programme is expected to have various types of impacts along different impact pathways (European Commission, 2018; Bruno and Kadunc, 2018), including societal impacts, the paper focuses on economic impacts in terms of GDP and employment. A key novelty in the approach is the triangulation of results from three macroeconomic models (NEMESIS, QUEST and RHOMOLO) for the assessment of the baseline scenario, i.e. the continuation of Horizon 2020 over 20212027. This exercise shows that the models tend to agree on the pattern and sign of the impact of the Framework Programme. However, the size of the impact seems to depend on the specificities of the models (this includes their elasticities and intrinsic mechanisms) and on assumptions related to the EU added value of public investments in RYI and the way the programme is funded in the models. These assumptions also affect directly the analysis of options related to more centralisation or decentralisaiton at the national level of the management of EU R\&I funding. Regarding EU added value, the higher performance of the Programme in the NEMESIS model is related to assumptions on higher performance and leverage compared to national funding. While there is strong evidence to support this EU added value, the quantification of its impact should be supported by further analyses. The empirical literature on this aspect is still poor and would benefit from additional contributions. Regarding funding, results from the QUEST model suggest that funding through VAT funding is more beneficial compared to lowering national investments. NEMESIS also shows that increasing the budget of Horizon Europe is much more impactful if it crowds out national public investments (except in R\&I) instead of national public support for R\&l.

Overall, past and current experience demonstrates the growing importance of macroeconomic modelling in the evaluation and impact assessment of EU RyI policy. Today, the need for state-of-the-art modelling approaches all along the policy cycle has never been so great. However, the complexity of the modelling exercise can make it challenging for policy-makers and modellers to collaborate with each other. It is not always simple to tailor a model to the specific needs of a precise R\&I intervention. For example, while budget allocation and size can be easily translated into the mechanisms of a model, changes in the design, content or priorities of a programme require careful reflection as there is not always a straightforward adjustement of parameters in the models that corresponds to these changes. However, it is in general possible to find a way to proxy in these models the options considered by the policy-maker.

In this respect, modellers should help policy-makers understand the key features and assumptions of their models. More generally, policymakers and modellers should collaborate closely with each other, hence allowing to better shape the things to come.

\section{REFERENCES}

Boitier, B., Le Mouël, P., and Zagamé, P. (2018). Support for assessment of socio-economic and environmental impacts (SEEI) of European R\&I programme. European Commission report.

Doi: $10.2777 / 038591$.

Bruno, N. and Kadunc, M. (2018). Impact Pathways: Tracking and communicating the impact of the European Framework Programme for research and innovation. Paper presented at the Austrian Presidency of the Council of the European Union Conference on Impact of Research and Innovation Policy at the Crossroads of Policy Design, Implementation and Evaluation in Vienna, Austria.

Corrado, C., Haskel, J., Jona-Lasinio, C. and Massimiliano, I. (2016). Intangible investment in the EU and US before and since the Great Recession and its contribution to productivity growth, ElB Working papers, 2016/08.

Delanghe, H. and Muldur, U. (2007). Impact assessment of research programmes: The experience of the European Union's 7th Framework Programme. Science and Public Policy, 34(3), 169-183.

Delanghe, H., Sloan, B. and Muldur, U. (2011). European research policy and bibliometrics indicators, 1990-2005. Scientometrics, 87(2), 389-398.

Di Comite F. and Kancs D. (2015). Macro-Economic Models for R\&D and Innovation Policies. IPTS Working Papers on Corporate R\&D and Innovation, 03/2015.

Dimos, C. and Pugh, G. (2016). The effectiveness of R\&D subsidies: A meta-regression analysis of the evaluation literature, Research Policy, 46(4), 797-815.

ECDG and Elsevier (2017). Overall output of select geographical group comparators and related FP7- and H2O20-funded publication output. Final Report, https://frama.link/C7wPJhGp.

European Commission (2013). The Grand Challenge - The design and societal impact of Horizon 2020. Directorate-General for Research and Innovation. Doi: 10.2777/85874.

European Commission (2015). Better Regulation Guidelines. Commission Staff Working Document. SWD(2015)110 final.

European Commission (2017a). The economic rationale for public Rq। funding and its impact, Policy Brief Series, Directorate-General for Research and Innovation, Doi: 10.2777/047015. 
European Commission (2017b). Interim Evaluation of Horizon 2020. SWD(2017)220, book.

European Commission (2017c). LAB - FAB - APP Investing in the European future we want: report of the independent High Level Group on maximising the impact of EU research \& innovation programmes. Directorate-General for Research and Innovation.

European Commission (2018). Commission Staff Working Document: Impact Assessment of Horizon Europe. SWD(2018)307 final.

Hall, B.H., Mairesse, J. and Mohnen, P. (2009). Measuring the Returns to R\&D. NBER Working Paper No. 15622.

Le Mouël, P., Le Hir, B., Fougeyrollas, A., Zagamé, P. and and Boitier, B. (2016). Toward a macro-modelling of European Innovation Union: The contribution of NEMESIS model. Paper presented at the 9th Conference on Model-based Evidence on Innovation and DEvelopment (MEIDE) the 16-17 June 2016 in Moscow, Russia. https://frama.link/8Gmb7fnM.

Muldur, U., Corvers, F., Delanghe, H., Dratwa, J., Heimberger, D., Sloan, B., Vanslembrouck, S. (2006). A new deal for an effective European research policy: The design and impacts of the 7th Framework Programme. Dordrecht: Springer.

PPMI (2017). Assessment of the Union Added Value and the Economic Impact of the EU Framework Programmes (FP7, Horizon 2020). https:// frama.link/060BPRZU.

Rosemberg, C., Wain, M., Simmonds, P., Mahieu, B. and Farla, K. (2016). Ex-post evaluation of Ireland's Participation in the 7th EU Framework Programme - Final Report. Technopolis Group, June. https://frama. link/9kXjUv_3

Vullings, W., Arnold, E., Boekholt, P., Horvat, M., Mostert, B., Rijnders-Nagle, M. (2014). European Added Value of EU Science, Technology and Innovation actions and EU-Member State Partnership in international cooperation - Main Report. Technolopis Group. doi:10.2777/1193.

\section{AUTHORS}

\section{JULIEN RAVET}

iCite, Solvay Brussels School of Economics and Management (SBS-EM, ULB), Belgium

E: julien.ravet@ec.europa.eu

\section{BAPTISTE BOITIER}

Société européenne d'économie (Seureco), France

MARCO GRANCAGNOLO

European Commission - DG Research and Innovation, Belgium

\section{PIERRE LE MOUËL}

Société européenne d'économie (Seureco), France

\section{LIVIU STIRBAT}

European Commission - DG Research and Innovation, Belgium

\section{PAUL ZAGAMÉ}

Société européenne d'économie (Seureco), France

\section{KEYWORDS:}

Research and Innovation Framework Programme, Horizon Europe, Exante impact assessment, Macroeconomic modelling, NEMESIS, QUEST, RHOMOLO

2 A high-level group chaired by Pascal Lamy was set up by the European Commission in order to provide advice on how to maximise the impact of the EU's investment in research and innovation (European Commission, 2017c).

3 Courtesy of DG ECFIN and DG JRC of the European Commission for the results of, respectively, the QUEST and RHOMOLO models.

$4 \quad$ Horizon 2020 allocations were calculated based on data from CORDA.

$5 \quad$ The direct leverage effect is the difference between the total subsidy (to support R\&l investments) received by an R\&I entity and the total R\&I expenditure engaged by this entity as the result of this support. For instance, if the direct leverage effect is positive (crowding-in), this means that the financial support received by the entity has a "multiplier" effect on the R\&l investments of this entity. In this case, total R\&l expenditures are higher than the financial support received.

6 Economic performance reflects the outcomes of investments in terms of sectoral value added or production (and GDP at national level). Economic performance of R\&D investments in the NEMESIS model is based on the empirical literature (e.g. Hall et al., 2009). With budget allocations being proportional to Horizon 2020 allocation.

According to GBAORD data (Eurostat), the share of project funding in total EU GBAORD is around 30\% (Boitier et al., 2018). By converting this amount in percentage value of the government public expenditures in R\&D, it amounts to about $26 \%$. Therefore, the centralisation of a third of the national competitivebased project funding at EU level is, on average, equivalent to centralise, at EU level, $8.75 \%$ of the government public R\&D expenditures in each member state, which represents around € 9 billion (constant 2014) per year.

9 With this $15 \%$ depreciation rate, more than half of the knowledge created today will become obsolete after 5 and half years.

$10 \quad$ In 2018 prices.

11 In 2018 prices 